\title{
Understanding Skill as the tools for evaluation
}

\section{through arts}

\section{Huidrom Rakesh Singh}

Research Scholar, Dept. Of Dance \& Music, Manipur University, Manipur, India

Email: rakesh huidrom@ymail.com

\begin{abstract}
The main aim of this paper is to point out the skills as a tools for evaluation through arts help in teaching method. To evaluate the various art form teacher must have the knowledge of the different tools which are discussed in this paper: tools of drawing, tools of dance, drama tools, project, portfolios, checklist, rating scale display.
\end{abstract}

Keywords-Evaluation, Tools of Arts, Skills.

\section{INTRODUCTION}

The various art forms activities lead to various changes in the student the changes may be in the intellectual, cognitive, reasoning, psychomotor etc and evaluation of these changes is very much needed. For students to show their talents and skills an opportunity or platform must be provided so that through these platforms the talented and skill students are identified.

Evaluation in art education is under taken to recognize progress of children in Various areas and identify areas which need further learning. At the elementary Level a teacher need not focus on the fine skills and knowledge of any art form. Children are supposed to express them according to their capacity and thinking. Freedom should be given to them to imagine, explore, innovate and then express.

One has to look at evaluation with the perspective of;

- Individual creativity

- Expression and the feeling that it conveys to us.

- Child's intention behind the art work

- Whether the purpose of the activity has achieved its goal

- To which scale

- Did the activity make any difference to the child's thinking?

- How is the art work fulfilling to the need of a child?

- How can he/she improve the work quality?

Evaluation is the systematic assessment of the worth or merit of a child's task. Everything the child thinks, expresses needs to be evaluated. It is the process of finding out the extent to which the desired changes have taken place. It is a part and parcel of teaching learning process. According to 'Vygotsky': "the job of an educator is to take the child from her 'present level' to 'potential level'." Periodic evaluation of children is important to determine whether the students are getting the benefits from the art activities. At the end of an art activity a teacher needs to get the feedback.

Hence the purpose of evaluation is:

To find out the progress the child has made over a period of time like:

- Knowledge of a particular subject.

- Creative experience of visual/performing art.

- Creative expression of one's perception of concepts.

- To assess the change that occurred in the child's personality.

- To identify individual and special needs and requirements in a child's being.

- To support \& improve children by making them release their potential.

- To provide suitable environment to help them develop their creativity.

- To enhance confidence of the children by appreciating their achievement \& communicate the same to their parents.

- To plan teaching learning situations in a more suitable way.

- To understand the child in terms of their social and emotional behaviour, their attitude \& values. 
Diagnosis exercise plays an important role in evaluation. It is evaluation through which the main problems are identified and areas or focus groups that need attention are known. The data in its original form cannot be used to draw Inferences. It needs to be converted in the form of indicators, so that meaningful conclusion is drawn. Indicator answers a variety of questions."An instrument which gives you information" is called indicator. Indicator is a Qualitative or quantitative variable that provides a simple and reliable means to measure achievement, to reflect changes connected to an intervention, or to help assess the performance. Indicators are about achievements but are never an end in itself.

Comprehensively the Development Indicators Are

Physical and Motor Development

- Stamina, and activity level

- Grace,

- Alertness,

- Eye - hand coordination

- Gross motor development,

- Fine motor development,

\section{Mental Development}

- Observation

- Memory

- Clarity of Concepts

- Problem - Solving

- Making sense of information

- Language development

- Creativity

- Logical Thinking

- Perceiving things, events etc.

\section{Socio-emotional Development}

- Relating to adults and peers

- Sharing with others

- Cooperation

Some of the skills that can be evaluated in visual arts are Artistic

- Seeing, drawing, and understanding form

- Mastering the use of colour, space and line

- Relating abstract ideas and visual forms

- Visualizing shapes and spatial relationships

- Utilizing theories of composition
Technical

- Knowing the qualities and limitations of each medium

- Working with a variety of media

- Attaining a high level of Craftsmanship

- Good finger and manual dexterity

- Working independently

- Communication

- Criticizing, evaluating, and explaining works of art file

\section{Problem Solving and Critical Analysis}

- Use critical thinking skills to evaluate and solve problems, demonstrate the ability to be creative and innovative in identifying solutions

- Analyse complex textual and cultural phenomenon

- Develop critical observations and attention to detail

- Pursue innovative and unconventional solutions: ability to take multiple approaches to problems

- Utilize available resources

- Demonstrate leadership

- Monitor the success of a project and identify ways to improve it

Interpersonal Abilities and Teamwork

- Establish good relations with the people you work with as well as respecting individual differences

- Work well with people from diverse backgrounds

- Work effectively within a group, demonstrating leadership

- Monitoring the success of a project and identifying ways to improve it

\section{Organization}

- Organize ideas and materials in an effective way

- Design, plan, organize and implement projects and tasks within an allotted timeframe

\section{Citizenship and Global Perspective}

- Integrates an awareness of how social, organizational, and global issues are interrelated with individual and local concerns

\section{Creativity}

- Think and write creatively

- Lead and participate in discussions 
- Effectively convey arguments and opinions and encourage independent and creative thought

\section{Some of the skills of performing art are \\ Teamwork}

You'll need to be able to listen to other team members and take on board each other's opinions and ideas.

\section{Technical ability}

You may need particular technical skills and specialist knowledge of how things work or need to be designed and built.

\section{Physical fitness}

You'll need to be physically fit, agile, and strong.

\section{Time management}

You'll need to be able to manage your time efficiently and make deadlines.

\section{Organisation}

You'll need to be able to plan and schedule work. This could include being able to prioritise what needs to be done and by when.

\section{Communication}

If your job requires verbal communication, you may need to write or give speeches and presentations. For jobs which require written communication skills, you will need to write clearly and convincingly - you could be producing or dealing with legal documents or writing articles for a newspaper. You may also require good listening skills, the ability to negotiate, or to be persuasive.

\section{Creativity}

You may need specific artistic or design skills for a job, or you may need to draw on a good imagination to come up with creative solutions to business challenges.

\section{Attention to detail}

You'll need to be thorough and focused on details of a task. You'll monitor and check work, information, or plans.

\section{Discipline}

You need to know and do what is expected of you. This ranges from organising yourself, being on time, to being responsible. Some jobs need particular discipline skills such as being able to persevere with the task and plans until you accomplish them, or following strict procedures.

\section{CONCLUSION}

All of us are familiar with the fact that the role of a teacher is not complete merely with organization and facilitation of art activity. Evaluation is an integral part of teaching learning process. The teachers must take a serious note of it. As we realize we can no longer afford to ignore the importance of art and hence evaluation process in art for supporting the child's development is extremely important. A teacher should observe student's struggle with creative problem solving, their willingness to try new things and their application of critical thinking. Final product of Art Work will give only a partial view of the child's experiences, understanding and development in the art. Ongoing observation is essential to achieve a complete and balanced assessment. While assessing products or performance in the art, the teacher may determine the extent to which students are achieving the learning objectives by observing the Individual art work, Portfolios, Audio Visual and displays. Teacher should interact with their children frequently

\section{REFERENCES}

[1] Blanche Jefferson (1963), Teaching Art to Children, United States of America Devi Prasad (1998), Art: The Basis of Education. National Book Trust, New Delhi.

[2] Jane Sahi \& Roshan Sahi, (2008), Learning Through Art, Ekalavya, Banglore. Manfred L. Keiler, (1955), art in the Schoolroom, University of Nebraska Press. Santidev Ghosh (1978), Music and Dance in Rabindranath Tagore's Education Philosophy, sangeet Natak Academi, New Delhi.

[3] Terence Wooff (1976), Development in Art Teaching, Open Book London. 